\title{
Begining open heart surgery in Nepal: Our experience and three years audit at Tribhuvan University Teaching Hospital
}

\author{
Dr. Bishwo Man Singh Shrestha, Dr. Bhagwan Koirala, Dr. Purna Raj \\ Joshi, Dr. Mod Nath Marahatta, Mr. Mahendra Bhatta, Dr. Rabindra Tim- \\ ila, Dr. Uttam Shrestha, Dr. Jyotendra Sharma, Dr. Paleswan Lakhey, Dr. \\ Sidhartha Pradhan, Prof. Govind Prasad Sharma*
}

\begin{abstract}
:
The historic first open heart surgery by the all-Nepalese team was performed at Tribhuvan University Teaching Hospital (TUTH) on 20 February 1997. Since then with-in three years period 132 cases of Open Heart Surgeries were performed. Retrospective study of those cases and problems faced in continuing the service is presented here.
\end{abstract}

The youngest patient was two and half years old and the oldest was 70 years of age with the mean age of 22 years. The number of patients suffering from congenital heart disease was 84 (64\%). Rheumatic heart disease (RHD) was found in 46 cases (35\%), bacterial endocarditis with severe valvular regurgitation, Ruptured Sinus of Valsalva (RSV), and cardiac tumour were diagnosed in 2 cases 1.5\%) each. There were 16 cases $(12 \%)$ with combined pathology. Preoperative clinical diagnostic error was established intra-operatively in 7 cases (5\%). Mild pulmonary artery hypertension (PAH) was present in 32 patients (24\%), whereas moderate in $76(58 \%)$ and severe in $24(18 \%)$. Direct closure of congenital defects was performed in 53 cases (40\%), where as patch closures in 29 cases (22\%). Open Mitral valvotomy was performed in 8 cases (61.5\%), single valve replacement in 33 patients (25\%), and double valve replacement (DVR) in 7 $(5 \%)$. Other types of operations and combined operations were performed in 8 patients (6\%). Post operative complication of significant bleeding and arrythmia occured in 23 patients $(17 \%)$. Thirty days hospital mortality occurred in 9 cases $(7 \%)$. Follow up of the patients was done from one month to 36 months. Postoperative remarkable improvement occurred in all cases except one case of cardiac tumour metastases. In three years period, there were 48 weeks when open heart surgery could not be performed for various reason.

We conclude that open heart surgery for simple congenital and RHD is successfully being done in Tribhuvan University Teaching Hospital and the Nepalese patients do not 
need to go abroad for the very expensive surgery. If the existing facilities at TUTH are improved and Cathlab and Trans Oesophageal Echocardiography (TOE) be added, there would be less preoperative diagnostic error and more complicated cases could be done safely by the experienced open heart surgery team.

\section{Introduction:}

Until 1997 no regular open heart surgery was performed in Nepal. There used to be sporadic short visits of foreign cardiac team in Nepal, but only a small number of patients benefited from such visit.

Most of the patients were also not able to travel even to India for the treatment, as it used to cost a fortune. This fact compelled us to establish open heart surgery service in Nepal itself. We had experienced al the difficulties in beginning the first regular open heart surgery in Nepal, mobilising the hospitals own limited resources. Despite such difficulties, a large number of cardiac patients had benefited from our services. The full commitment, dedication and hard working ofall the team members made this program a success.

\section{Materials \& Methods:}

All the patients admitted at the Department of Surgery of Tribhuvan University Teaching Hospital for open heart surgery in the period between February 1997 and February 2000 were studied retrospectively. All the data were collect from the OR, ICU, and the patient records and follow up charts.

All the patients were diagnosed with the use of 2-D and colour Doppler echocardiaography. Cardiac catheterisation was performed in three patients $(2.3 \%)$ to confirm the following diagnosis of ASD with partial anomalous pulmonary venous drainage (PAPVD), Mitral Stenosis with severe PAH, and superior Vena Cava tumour. In 12 patients (9\%) with congenital defect, Swan Ganz Catheterisation was performed for direct evaluation of the shunt and pulmonary artery pressure (PAP). The mild PAH was considered when PAP was below $35 \mathrm{mmHg}$, moderate when between 36 to $5 \mid 0 \mathrm{mmHg}$, and severe when above $51 \mathrm{mmHg}$.

\footnotetext{
* Cardiothoracic unit, Department of Surgery, Tribhuvan University Teaching Hospital, Maharajgunj, Kathmandu, Nepal
} 
The patients were followed up from one to thirty six months with clinical examination, EKG, Chest X-ray and echocardiography.

\section{Results:}

In the three years period a total of 132 patients were admitted for open heart surgery. Male to female ratio was 64/68 (094:1.0). The youngest patient was of 2.5 years and the oldest was 70 years with the mean age of 22 years.

Fig. 1: types of cases admitted for open heart surgery: ASD (Arterial Septal Defect), OS (Ostium Secundum), OP (Ostium Primum), VSD (Ventricular Septal Defect), Single Art. (Transposition of great arteries with single atrium), RHD (Rheumatic heart disease), BE (Post bacterial endocarditis valvular disease), AV (aortic valve), RS V(Ruptured sinus of valsalva), Tu. (Tumor)

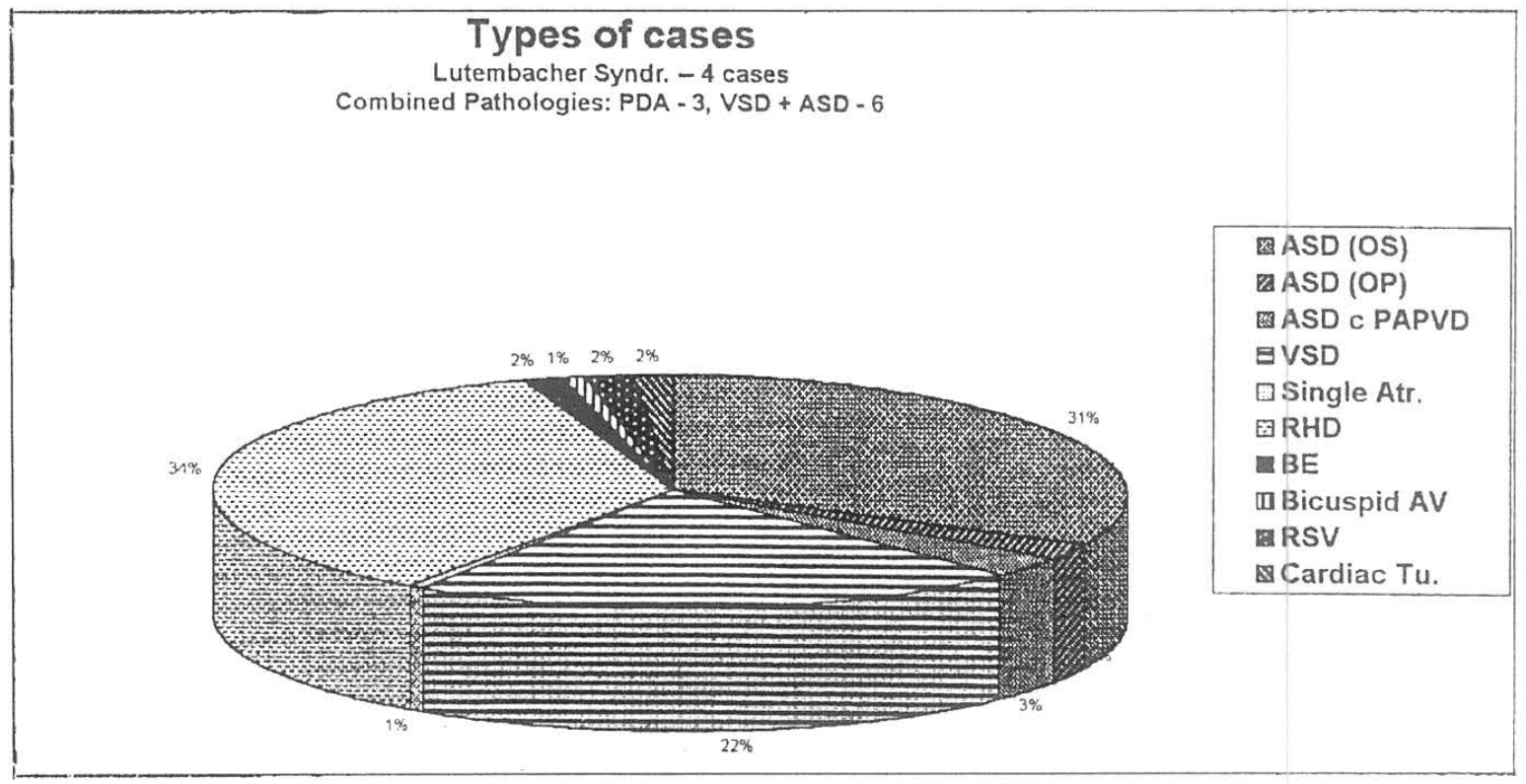

There were 16 patients (12\%) with combined pathologies such as congenital defect with Patent Ductal Arteriosus (PDA) in 3 cases, severe Mitral Regurgitation in 3 cases and VSD with ASD in 6 cases. There were 4 cases of Lutembacher syndrome. Error on preoperative clinical diagnosis occurred in 7 cases (5\%) which was diagnosed intraoperative only. They were as follows: 2 PDA, 2 ASD with PAPVD, 1 Mitral Stenosis without left atrial clot, 1 subvalvular aortic Stenosis, and 1 single atrium with dextrocardia and transposition of great arteries. Clinically the patients were in New York Heart Association (NYHA) class I in 28 cases (21\%), class II in 53 cases (40\%), class III in 41 cases $(31 \%)$, and class IV in 10 cases $(7.6 \%)$. 
Fig. 2: Preoperative Electrocardiograph diagnosis of Pulmonary Artery Hypertension
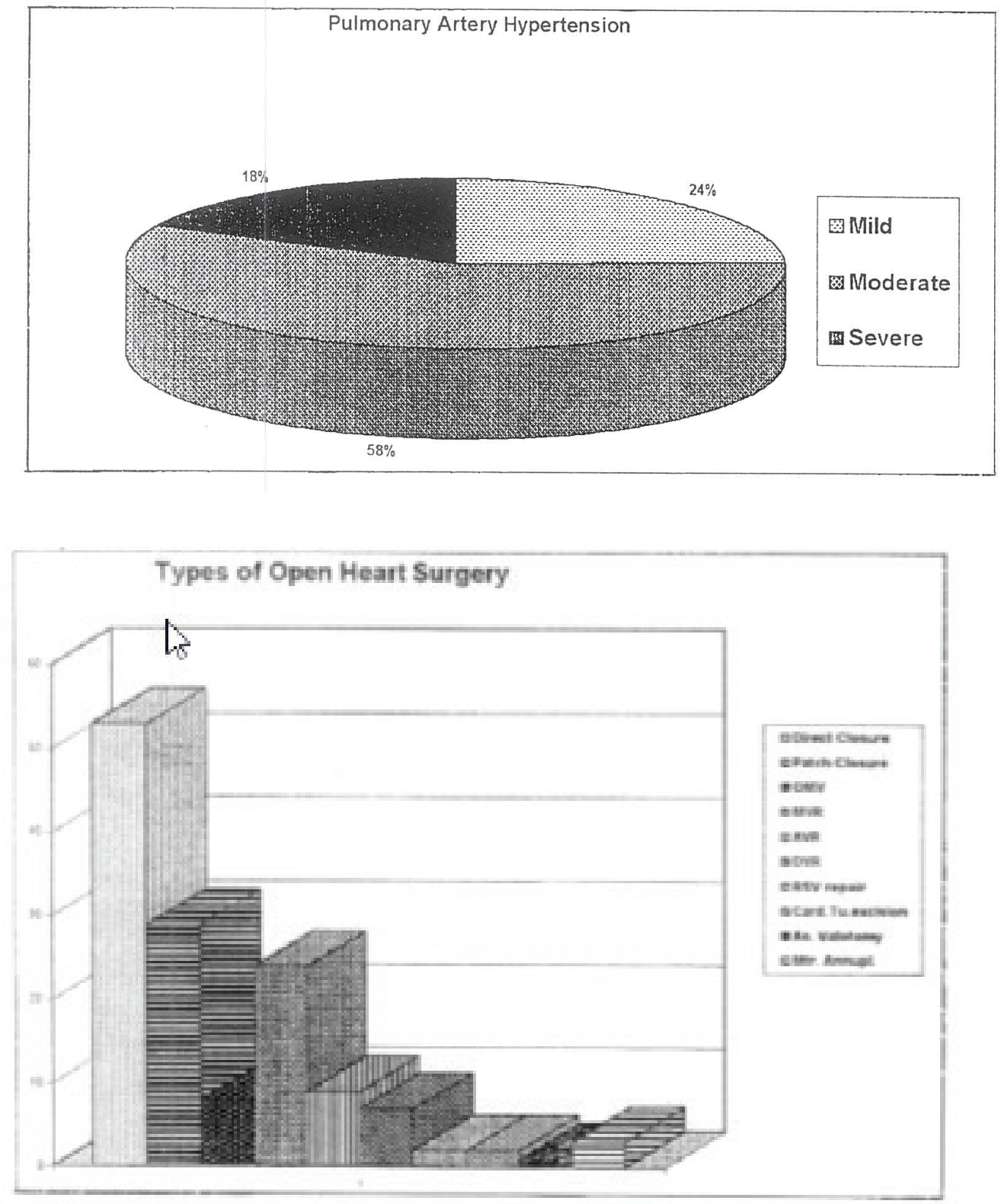

Fig. 3: Types of open heart surgery performed in the three years period: Direct closure (direct closure of congenital defect), Patch closure (pericardial or Dacron patch closure of the congenital defect), OMV (Open Mitral Valvotomy), MVR (Mitral Valve Replacement), AVR (Aortic Valve Replacement), DVR (double Valve Replacement), RSV repair (Ruptured sinus of valsalva repair), Card. Tu. excision (Cardiac tomor excision), Ao. Valvotomy (Aortic valvotomy in Bicuspid aortic valve), Mtr. Annupl. (Mitral Annulopasty)

All the operations were performed under cardiopulmonary bypass (CPB) using membrane oxygenator. The minimum CPB time was $18 \mathrm{~min}$. in a case of VSD closure and the longest time of 3:15 min. was in double valve replacement. The mean CPB time 
was $62 \mathrm{~min}$. The shortest aortic cross clamp time of $6 \mathrm{~min}$.was in ASD closure, where as longest time of 225 min was in Mitral valve replacement with the mean aortic X-clamp time of $42 \mathrm{~min}$. In 74 cases (56\%) CPB was done under hypothermia between 35 to 28 degree centrigrade, whereas remaining 58 cases (44\%) were done under normothermia. Crystalloid cold cardioplegia was used in 116 cases (88\%), and blood cold cardioplegia in 16 cases $(12 \%)$. Extubation on the operation table was performed in 79 patients $(60 \%)$, where as extubation with-in 4 hours of the operation was done in 28 cases $(21 \%)$, between 4 to 12 hours in 19 cases (14\%) and over 12 hours in 6 cases $(4.5 \%)$. In 10 cases $(8 \%)$ re-exploration for the bleeding were done. Postoperative significant arrhythmia occurred in 13 cases $(10 \%)$.

Fig. 4: Operations and the mortality in accordance to the trimester period Fig. 5: 30 days hospital mortality

Fig.6: Postoperative clinical result: NYHA (New York Heart Association classification)

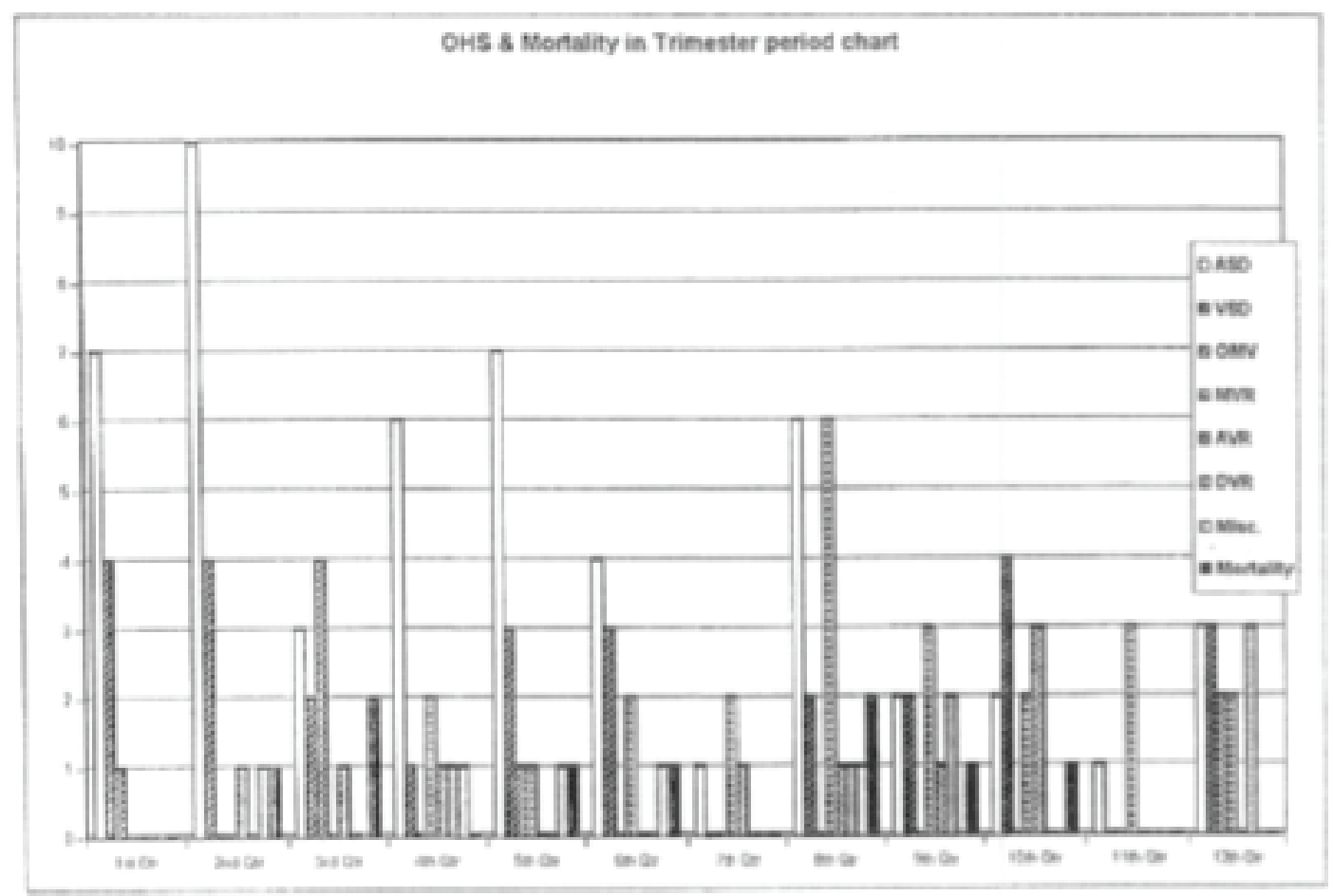


- NEPALESE HEART JOURNAL •
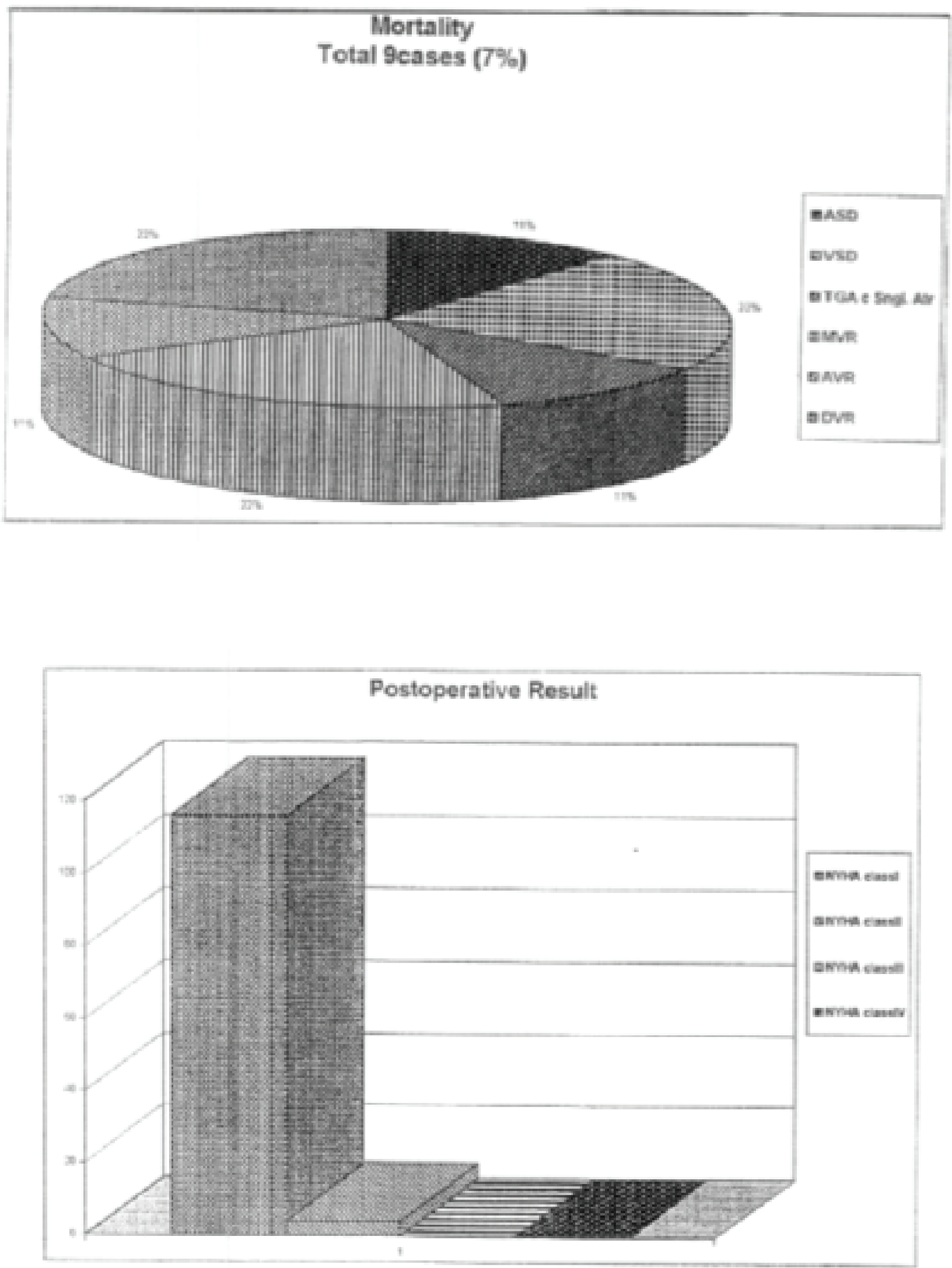
In the hospital the operation is done only once in a week but there were 48 weeks in this period when open heart surgery could not be performed. The reasons for it were as follows: (i) lack of ICU bed, (ii) break-down of instruments and machines, (iii) lack of enough supplies of disposables, and (iv) lack of enough trained manpower.

Fig. 7: The reasons and periods of operation cancellations: ICU beds (No vacant intensive Care Unit bed on the day of operation), Mechanical (break down of the machines needed for the operation), Disposables (Unvaibility of disposables needed for the surgery), Manpower (Absence of the trained team member)

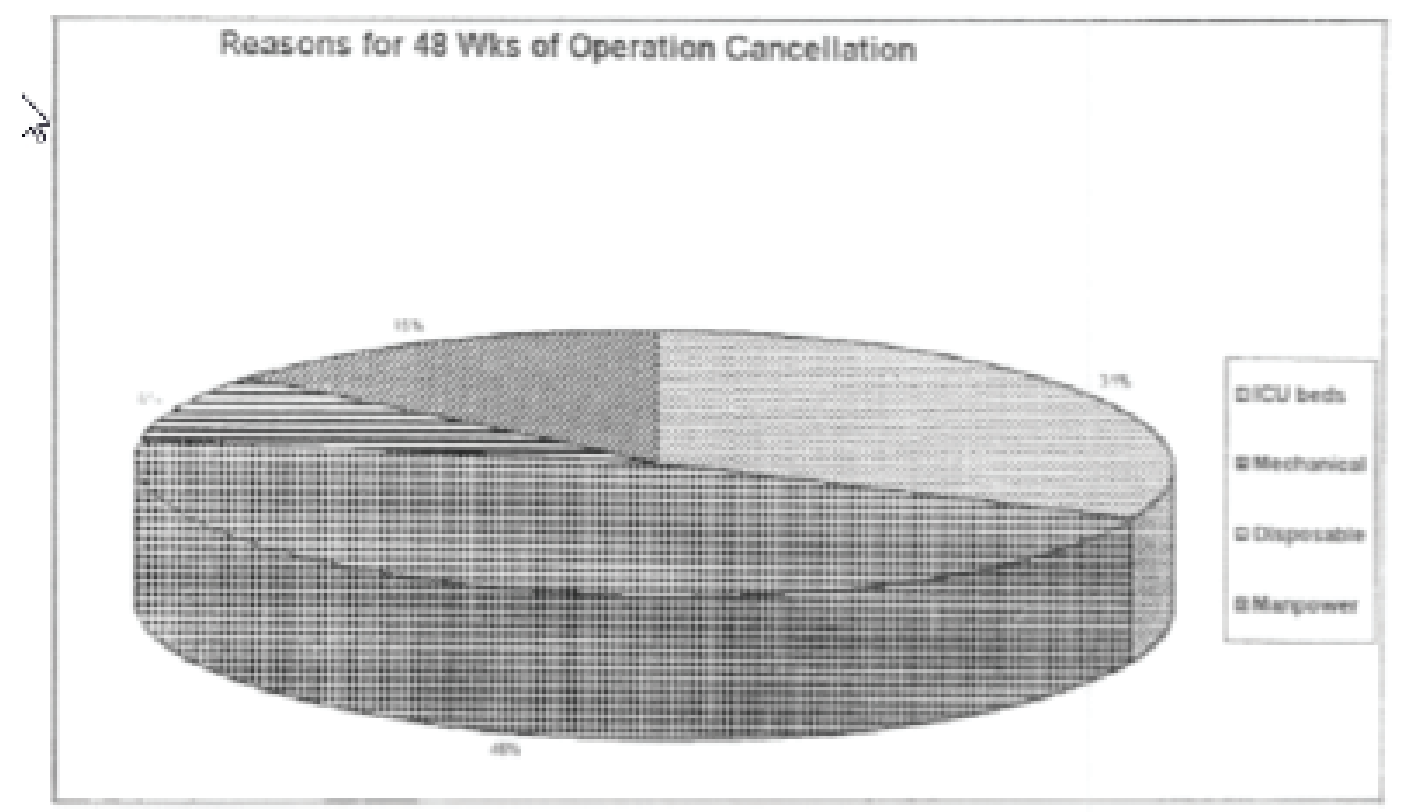

\section{Discussion:}

It is always difficult to begin new service more over super-specialised subject like open heart surgery when the infra structure for it is not available in the country. ${ }^{1,2}$ After basic training abroad, the surgeons, anaesthetists, perfusionist and nurses of TUTH initiated to form all-Nepalese open heart surgery team. The team assembled donated old instruments and machines for open heart surgery, tested them and even did few dummy practices to boost the confidence. The team also mobilised the local dealers to make available disposables, oxygenators and the prosthetic valves in the country.

With such effort and dedication of the team, now open heart surgery has become a routine procedure at TUTH. 
Due to lack of enough trained manpower the operation days could not be increased more than once a week in the past three years. Now after more than three years exposure of open heart surgery, there are enough trained man power in the hospital for the possibility to increase the operation day and number of operation cases per week. In the past three years period, there were significant number of weeks without operation which could have been minimized if the hospital had enough budget to solve the problems ${ }^{3,4}$. As to this date the Government of Nepal has not provided the needed financial support for the development of open heart surgery at Tribhuvan University Teaching Hospital. With the limited budget, the hospital was able to purchase only few spare parts of the old instruments and machines, but was not able to buy modern machines for the open heart surgery. Also there is urgent need to build a separate cardiac ICU ${ }^{4,5}$, as the six bed ICU in the hospital is being used as a general ICU. The hospital has all the potential to improve its quality of services and to increase the number of operations per week if the existing problems are managed by acquiring a separate budget for it.

In Nepal we still do not have fully equipped heart centre and a functioning cathlab, therefore most of the cases were diagnosed with echocardiography. In suspected cases of severe pulmonary hypertension Swan Ganz catheterization were performed. Most of the patients were in the group of moderate pulmonary hypertension, but the team had also performed operations on cases with severe $\mathrm{PAH}$ and most of them had improved significantly after it. For the first four months the team had performed only simple congenital defect repairs. When the teams' experience and confidence increased, then it started performing more complicated surgeries and valve surgeries with valve replacement as well. With increase number of cases done, the teams' performance result had significantly improved, Now the cardiopulmonary bypass time and aortic cross clamp time has shortened significantly, the morbidity and mortality has also become less than that in the beginning. ${ }^{6}$

Now the cardiac team of TUTH is quite confident in treating simple congenital defects and valvular disease in all age patients. The cautious approach of the team for the performing new complex surgeries without intraoperative and postoperative supportivemechanical devices such as 'Trans-Oesophageal Echocardiography transducer (TOE), cardiac out-put monitors and Intra-Aortic Balloon Pump (IABP), was the reason for not performing complex congenital heart diseases and coronary artery bypass surgery $(C A B G)$ yet. A large number of patients had already benefited from the regular open heart surgery service the team began during 1997 . The cost for the surgery in Nepal is almost two to three times cheaper than that of neighbouring country, where extra cost of travelling and lodging for the patient party has also to be added. Therefore now, even the 
lower middle class and poor patients could afford the surgery in Nepal, which otherwise was impossible for them to have it done abroad. Also there are other advantages of having surgery at home country, such as not having problems about lodging, foods, and arrangement of blood and blood products.

After the establishment of regular open heart surgery at TUTH, a large number of hospital staffs and residents got the exposure and training on the subject. Now it has also become easier for other cardiac centres in Nepal to begin regular open heart surgeries.

\section{Conclusion:}

- Open Heart Surgery for simple congenital and RHD is possible in Nepal and the Nepalese patients do not need to go abroad for the very expensive surgery.

- If the existing facilities at TUTH are improved, there would be less preoperative diagnostic error and more numbers of complicated cases could be done safely by the experienced open heart surgery team of TUTH.

- There is urgent need for separate budget for the open heart surgery program at TUTH. The Nepalese Government should provide the fund for the continuity and development of the already established and functioning program.

\section{Acknowledgements:}

The open heart surgery team of Tribhuvan University Teaching Hospital shows its gratitude towards all the staffs of the Department of Surgery, Department of Anaesthesia, Department of Medicine, Department of Pathology and Department of Maintenance for their continuous physical and moral support. The regular open heart surgery program would not have succeed, if it was not for the selfless care of OR, ICU, CCU and surgery ward nurses. We highly appreciated all the encouragement and support given by the hospital management. 


\section{References:}

1. Zurbrugg HR, Piehler S, Weiss HM. How to run a Heart Surgical Unit, Experiences during the first year of the Department of Cardiothoracic and Vascular Surgery, University Clinic of Regensburg. J Cardio Vassde. Surg. 1997; 38: 53-61.

2. Willimas T.E Jr, Fanning WJ, Link L, Benton WC, Kakos GS, Miller RL et al. Can we afford to do cardiac operations in 1996? A risk reward curve for cardiac surgery. Ann. Thorac. Surg 1994; 58 (3): 815-20.

3. Hamilton A, Norris C, Wensel R, Koshal A. cost reduction in cardiac surgery. Ann Thorac. Surg. 1993; 10(7): 721-7.

4. Havill JH, Moore JE, Armistead S, Ullal R. Open heart surgery: intensive care component, clinical profile and costs over one year. N.Z. Med J 1992; 105 (926):3-5.

5. Chong LJ, Pillai R, Fisher A, Grebenik C, Sinclair M, Westaby S. Cardiac surgery: moving away from intensive care. Br. Heart J. 1992; 68:430-3.

6. Klima U, Garabedian H, wimmer-Greinecker G, Traum J, Brucke P. Influence of case scheduling on outcome in cardiac surgery. J. Cardio Vasc. surg. 1997;38: 63-8. 